\title{
Personalidad criminal en un militar de elite entrenado y asesinato.
}

\section{Criminal personality in a trained elite military and assassination.}

DOI: $10.46932 / s f j d v 2 n 4-043$

Received in: May 1st, 2021

Accepted in: Jun 30th, 2021

\author{
Dr. Bernat-Noël Tiffon Nonis \\ Universitat Abad Oliba-CEU. Calle de Bellesguard, no30. 08022 Barcelona (Spain). \\ E-mail: btiffonn@uao.es
}

\section{RESUME}

El artículo tiene como objetivo explicar los rasgos de personalidad de base en un caso de asesinato perpetrado por un sujeto que desarrolló actividades profesionales en el campo militar de élite (era un francotirador especializado en misiones especiales en el extranjero), y qué repercusiones o consecuencias jurídico-legales tuvo por un delito de homicidio (de un civil) que perpetró, y la sentencia dictada al efecto.

Palabras clave: Personalidad, asesinato, militar de élite, capacidad cognitiva, capacidad volitiva.

\section{ABSTRACT}

The article aims to explain the basic personality traits in a case of murder perpetrated by a subject who developed professional activities in the elite military field (he was a sniper specialized in special missions abroad), and what repercussions or legal-legal consequences he had for a crime of homicide (of a civilian) that he perpetrated, and the sentence handed down to that effect.

Key words: Personality, assassination, elite military, cognitive capacity, volitional capacity.

\section{INTRODUCCIÓN}

El presente artículo pretende explicar los rasgos de personalidad de base en un caso de asesinato perpetrado por un sujeto que desarrollaba actividades profesionales en el ámbito militar de élite (era francotirador especializado en misiones especiales del extranjero) y qué repercusiones o consecuencias jurídico-legales le supuso en el delito de asesinato (a un civil) que perpetró y la sentencia emitida a tales efectos.

De este modo, se trata de un varón de 24 años, natural de los Países del Este, de estado civil soltero y nivel académico equivalente a estudios secundarios. Adoptado desde la edad de los 8 años en el seno de la familia española.

Hay que señalar que el informado presentaba antecedentes de disfunción mental durante su infancia los cuales fueron frutos de adversidades experimentadas:

- Fue objeto de violencia doméstica en el seno de su familia biológica hasta la edad de los 8 años (aprox.) ejercidos por su padre biológico. 
- Objeto de violencia en el seno del internado por el que fue ingresado a raíz de la violencia domestica ejercida su padre contra su propia familia y esposa (Violencia de Género).

- Problemas de baja motivación escolar durante su etapa de estudiante en el marco de la enseñanza española una vez adoptado por su familia de acogida.

- Problemas de conducta derivados de su vinculación a un grupo Neonazi.

- Éstas dos últimas circunstancias, refiere el informado, motivaron que pudiera ser diagnosticado de Trastorno de Déficit de Atención con Hiperactividad (TDAH), pero que no se llegó a confirmar dicho extremo ante la falta de historia clínica que pudiera confirmarse.

- Padre (biológico) fallecido por consumo crónico de alcohol.

Cuando se perpetraron los hechos (asesinato en el domicilio de la víctima) a raíz de una importante y fuerte discusión con un vecino a quien le propinó 30 puñaladas, el informado trabajaba como militar profesional como Soldado-Francotirador en La Legión (de un país de la Europa Occidental), perteneciendo a una sección especializada en Anti-Terrorismo.

El informado ingresó en un Centro Penitenciario de Madrid por delito contra la vida humana independiente.

Figura 1. Esquema del domicilio donde ocurrió el crimen. Escena del crimen.

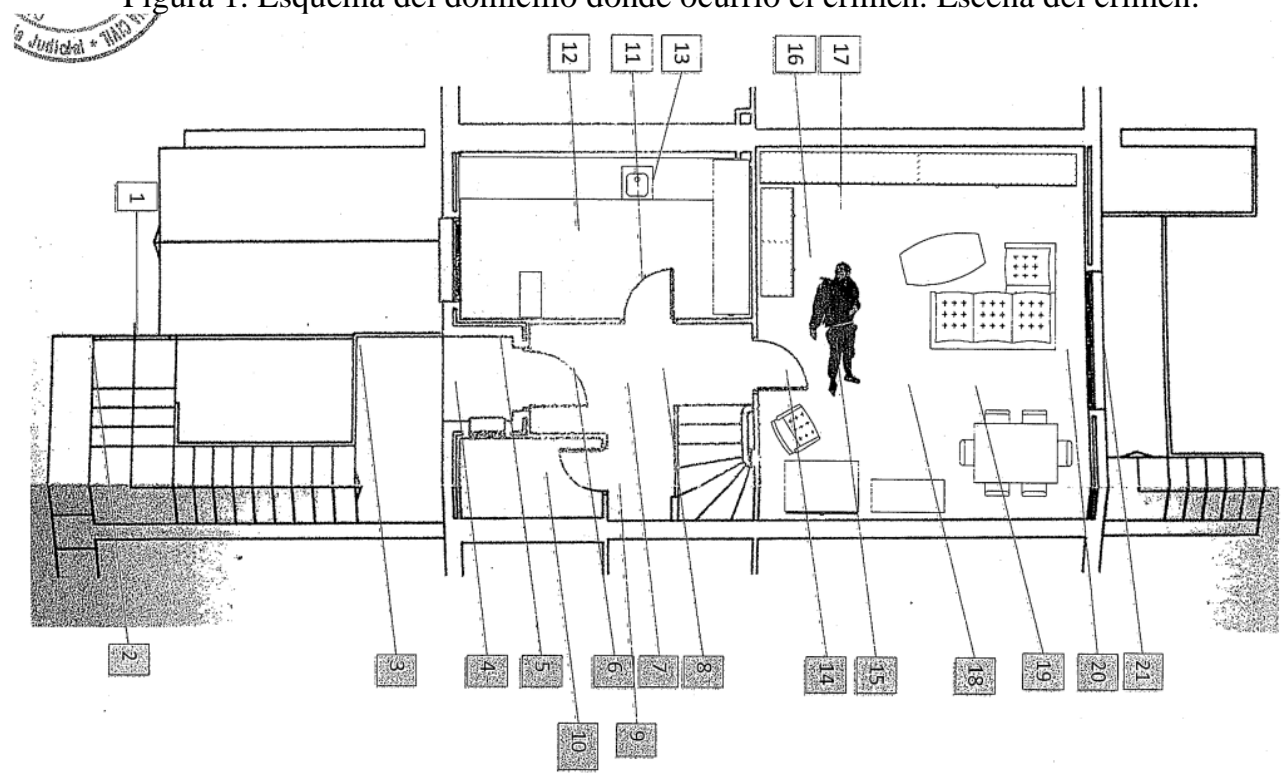


Figura 2: Arma blanca utilizada para la comisión del delito.

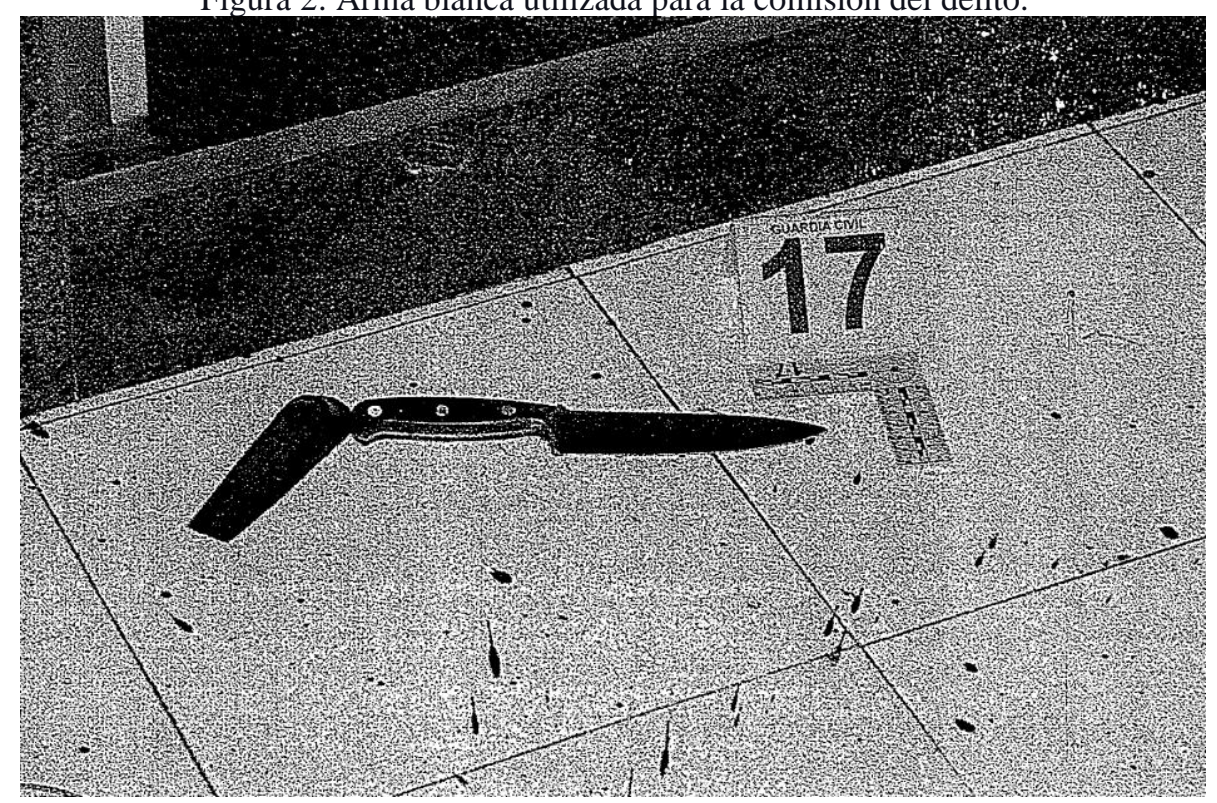

\section{RESULTADOS}

Para el desarrollo del estudio de la personalidad del informado se procedió a la siguiente metodología:

- Entrevista clínico-pericial dirigida (anamnesis) con el informado con una inversión total de horas aproximadas de 4-5h. en un Centro Penitenciario de la Comunidad Autónoma de Madrid.

- Administración actualizada de pruebas psicométricas con objeto a evaluar su estado psíquico y psicopatológico (MCMI-3; PAI; 16PF; Cuestionario Salamanca de Trastornos de Personalidad; STAI; BIS-11; Escala de Trauma de Davidson -DTS- y el SIMS.

- Análisis de la documentación clínica y jurídica aportada.

A raíz de la administración de los cuestionarios psicopatológicos y de la entrevista clínica dirigida celebrada, los resultados obtenidos vienen a sugerir que el informado presenta:

- Ausencia de Trastorno Mental Grave y/o Severo (ni pretérito ni activo).

- Presencia de Trastorno de la Personalidad.

- Presencia de graves rasgos disfuncionales de Personalidad de inestabilidad emocional (LímiteBorderline) sobre una base de tipo paranoide, anancástico-obsesivo y dependiente.

- Índice de simulación (SIMS) no significativo por lo que se desprende que su grado de sinceridad y fiabilidad se encuentra en la normalidad y acorde a su nivel sociocultural e intelectivo.

Complementariamente, se apreció un estado ansioso-obsesivo que se compatibiliza con un: 
- Trastorno Adaptativo Mixto Ansioso-Depresivo (código F43.22 de la CIE-10), circunscrito a la causa jurídico-legal por la que se encuentra sometido y con componente residual traumático derivado de su patobiografía (Tiffon, 2016).

\section{DISCUSIÓN/CONCLUSIONES:}

Con relación al motivo de consulta conforme se solicitaba si mantenía o no sus facultades cognitivas/volitivas en el momento de perpetrar los hechos, se concluyó lo siguiente para la elaboración de la pericial psicológica:

1. En el momento de perpetrar los hechos, el informado pertenecía a una unidad de élite militar: Francotirador experto en objetivos antiterroristas perteneciente al cuerpo del Ejército de la Legión y adiestrado en el entrenamiento de la "lucha cuerpo a cuerpo".

Ámbito profesional del cual, supuso para el informado, y en el ejercicio de sus funciones, vincularse en misiones y encomiendas oficiales de alta responsabilidad militar y con alto riesgo para su integridad física, y que, a épocas actuales, refiere "sentirse traumatizado" por el objeto de algunas misiones que se le encomendó llegando a matar a civiles (entre ellos, niños y mujeres).

2. Todo el conjunto de información recabada perteneciente a la patobiografía del informado, y en función de lo clínicamente explorado por el Perito que suscribe, en el momento de perpetrar el presunto los hechos acaecidos, todo pueda ser compatible con que el referido presentó una aguda y crítica alteración psico-emocional momentos previos a la comisión del suceso, como efecto de los sucesos precursores que experimentó como perjudiciales contra su persona e integridad física (tal como que la víctima "volvió con un cuchillo y él puso la mano derecha para defenderse y ese señor se lo quería clavar en la cabeza”, (...) “que la víctima vino de frente le pone el cuchillo en la cabeza y le quería cortar de arriba a abajo”, según declaración del detenido ante SS .

Lo que abocó a que el mismo experimentara la nociva excitación e impulsividad propia de la agudización paranoide agresiva u hostil (rasgos de personalidad Clúster A y B) y, fruto asimismo, de su actividad profesional de militar de élite, sufriendo una efímera alteración de su conciencia y de su capacidad crítica, de intensidad suficiente como para romper los mecanismos inhibitorios de su conducta y manifestándose comportamentalmente de la manera altamente nociva en la que se derivó, y no pudiendo valorar -en esos precisos instantes- el alcance de las consecuencias fatales que suponía la perpetración de dicha dañina acción.

3. A falta de psicopatología o trastorno mental mayor entendemos que el informado pudo padecer, a consecuencia de la agudización de los rasgos paranoides antes expuestos, una alteración del estado de ánimo y de las emociones de manera repentina y aguda que diera lugar a la explosión conductual impulsiva, súbita e inmediata de una alto grado de agresividad causado por la circunstancia que 
provocó los hechos que se enjuician, provocándole una disminución de las capacidades cognitivoreflexivas, e influyendo nociva y negativamente, en las volitivas de su conducta y de las consecuencias que conllevara. 


\section{REFERENCIAS}

- $\quad$ Tiffon, B.N. (2015). "Los Crímenes de Perejil”. J.M. Bosch Editor. Barcelona.

- $\quad$ Tiffon, B.-N. (2016). “Archivos Delictivo-Criminológicos”. J.M. Bosch Editor. Barcelona.

- $\quad$ Tiffon, B.-N. (2017). “Atlas de Psicología Forense (Penal)”. J.M. Bosch Editor. Barcelona.

- $\quad$ Tiffon, B.-N. y Cols. (2019). “Atlas Práctico-Criminológico De Psicometría Forense (Volumen I): Asesinatos". J.M. Bosch Editor. Barcelona.

- $\quad$ Tiffon, B.-N. y Cols. (2019). “Atlas Práctico-Criminológico De Psicometría Forense (Volumen II): Tentativas De Asesinatos”. J.M. Bosch Editor. Barcelona.

- $\quad$ Tiffon, B.-N. (2021). "Criminal and Forensic Psychology of a Case of Filicide by Decapitation of a Minor". Journal of Forensic Medicine. Case Series. Volume 6:3. ISSN: 2472-1026

- $\quad$ Tiffon, B.-N (2021). "Murder induced deliriously by a "folie à deux". Vol. 2 No. 2 (2021): South Florida Journal of Development, Miami, v. 2, n. 2, apr.jun. 2021 ISSN: 2675-5459 Págs. 3560-3564 Págs. 3560-3564

- $\quad$ Tiffon, B.-N (2021). "Amok syndrome in a quadruple crime, acting out and pathological drive.". Vol. 2 No. 2 (2021): South Florida Journal of Development, Miami, v. 2, n. 2, apr./jun. 2021 ISSN: 26755459 Págs. 3549-3554. DOI: https://doi.org/10.46932/sfjdv2n2-189

- $\quad$ Tiffon, B.-N (2021). "Criminal personality in a trained elite military and assassination". Vol. 2 No. 2 (2021): South Florida Journal of Development, Miami, v. 2, n. 2, apr./jun. 2021 ISSN: 2675-5459 Págs. 3555-3559. DOI: https://doi.org/10.46932/sfjdv2n2-190

- $\quad$ Tiffon, B.-N. (2021). "Double filicide for extended suicide (frustrated) of a subject with major psychotic depression and dependent personality disorder". South Florida Journal of Development, Miami, v. 2, n. 3, Special Edition, jul. 2021. Págs. 4552-4562. DOI: https://doi.org/10.46932/sfjdv2n3-057

Tiffon, B.-N. (2021). "Delusional psychotic disorder, substance use and murder with alevosia and cruelty". South Florida Journal of Development, Miami, v.2, n.3, p.4544-4551 Special Edition, jul. 2021. Págs. 4544-4550. DOI: https://doi.org/10.46932/sfjdv2n3-056

- $\quad$ Tiffon, B.-N. \& González-Fernández (2021). "Amok Syndrome. Qualified Perspectives on an Aggressive Reaction of Pathological Impulsiveness in The Perpetration of a Double Crime with a Firearm". ASEAN Journal of Psychiatry, Vol. 22(S2), June 2021: 1-5. ISSN: 2231-7791

- $\quad$ Tiffon, B.-N. \& González-Fernandez, J. (2021). Alcohol Consumption and Intensification of Paranoid Traits in Attempted Homicide. ASEAN Journal of Psychiatry, Vol. 22(4), June 2021: 1-5. ISSN: 2231-7791 